International Journal of Linguistics, Literature and Culture
Available online at https://sloap.org/journals/index.php/ijllc/
Vol. 5, No. 5, September 2019, pages: 7 14
$\begin{aligned} & \text { ISSN: 2455-8028 } \\ & \text { https://doi.org/10.21744/ijllc.v5n5.727 }\end{aligned}$

\title{
Application of Self-Evaluation and Co-evaluation on Learning Processes
}

\author{
CrossMark
}

Antonia Betty Gomez Vera ${ }^{\text {a }}$ Mercedes Katherine Gomez Vera ${ }^{\text {b }}$ Aidee Monserrate Ramos Garcia ${ }^{\mathrm{c}}$ María Janeth Vélez Miranda ${ }^{d}$

Article history:

Received: 18 March 2019

Accepted: 31 July 2019

Published: 01 September 2019

\section{Keywords: \\ aprendizaje; \\ autoevaluación; \\ coevaluación; \\ enseñanza; \\ evaluation;}

\begin{abstract}
One of the important points within the evaluation is who performs it, long ago it was understood that the evaluation always came from an external instance to the evaluation, which was usually the teacher. Self-assessment is when the student is evaluated, while co-evaluation is when the group evaluates in a reciprocal way, encouraging participation, critical and constructive reflection, identifying achievements and shortcomings within the process of Learning. This article aimed to identify the application of selfassessment and co-evaluation in learning processes, where the research was of exploratory type, the scientific method was applied, synthetic analytical, gave as end result that teachers know the importance of these evaluative practices, because of situations of conformity, monotony, and fear of causing enmities with students do not use them.
\end{abstract}

2455-8028 ${ }^{\circledR}$ Copyright 2019. The Author. This is an open-access article under the CC BY-SA license (https://creativecommons.org/licenses/by-sa/4.0/) All rights reserved.

\section{Author correspondence:}

Antonia Betty Gomez Vera,

Master's student of the Pontificia Universidad Católica del Ecuador, Sede Manabí, Portoviejo.

Email address: agomez6953@pucem.edu.ec

\section{Introduction}

This article, carried out after observing the poor application of self-assessment and co-evaluation in classroom learning processes, is intended to make teachers aware of the importance of these types of assessments and to consider them as a key method in the learning-teaching process, thus creating awareness and thus fostering responsibility in students for the development of their personal and academic growth, based on motivation, constancy, perseverance as well as manifests it (Rodríguez \& Hernández, 2014), who proposes that students should

${ }^{a}$ Pontificia Universidad Católica del Ecuador, Sede Manabí, Portoviejo, Ecuador

${ }^{\mathrm{b}}$ Pontificia Universidad Católica del Ecuador, Sede Manabí, Portoviejo, Ecuador

${ }^{\text {c }}$ Pontificia Universidad Católica del Ecuador, Sede Manabí, Portoviejo, Ecuador

${ }^{\mathrm{d}}$ Pontificia Universidad Católica del Ecuador, Sede Manabí, Portoviejo, Ecuador 
be the protagonists of their own learning process also obtaining the ability to make valuable judgments and constructive criticism when evaluating other colleagues.

This research was carried out in the Unidad Educativa Fiscal Alejo Lascano city of Jipijapa where it is intended to encourage teachers to apply self-assessment and co-evaluation in the learning processes of students within the classroom, as well as to actively involve the educating of these evaluative forms, which will help them share, discuss with them the purposes and expected results both individual and group where they can reflect on their experiences, value their strengths and needs.

\section{Materials and Methods}

This research work is exploratory, the scientific method and synthetic analytical were applied; the fieldwork was carried out with the teachers of the Unidad Educativa Fiscal "Alejo Lascano" where the 25 teachers in the evening session were surveyed. The results were processed and analyzed in the light of the theories consulted; the survey technique that allowed the collection of information to those involved in the investigation was applied.

\section{Results and Discussions}

\section{Self-assessment}

Self-assessment should be instilled in students gradually in the classroom and with certain degrees of complexity, depending on age and development. Through this evaluation moment, both the agent (students) and the object (themes, contents) are unify and identify, therefore (Pastor et al., 2005; Bordelois et al., 2018), manifest that this process is an experience where students learn to be aware attitudes, behavior, and learning. All this is achieved according to predetermined self-assessment criteria such as coexistence rules, rubric in terms of the contents of the subjects seen in a particular period.

Self-assessment becomes a methodological procedure that allows the student to be able to assess what he does responsibly, consents, fostering autonomous learning with judgments and criteria that help him to make sound decisions in the Right moments (Cruz \& Quiñones, 2012; Macías et al., 2018), states that this technique must have ordered, in order for the educating to gradually show his progress, must also raise awareness to reach a discussion and internal reflection of the results for the respective future decision-making.

\section{The rubric as an instrument for self-assessment}

Conducting an appropriate self-assessment implies, like any didactic process that must consist of adequate design, information and preparation, it is, therefore, necessary to know that the techniques and instruments to be used, the characteristics of the modality evaluation, and how to express the results. The rubric is a test that serves to outline consistent evaluation criteria by allowing teachers, students, to evaluate complex and objective criteria, as well as provide a framework for self-assessment, reflection, and peer review. It aims to achieve a fair and sound assessment, foster understanding and indicate a way to proceed with consistent learning/teaching. Figueira et al., (2013), state that the use of rubrics not only promotes a more systematized evaluation by the teacher, but they are a tool of extraordinary value for the development of monitoring, self-assessment and evaluation skills between contributing to a greater understanding of the learning process itself and, ultimately, to greater autonomy and selfregulation of the student.

\section{Types of rubric}

The rubrics can be applied to different activities and at different times of the learning process, as well as be used by all the agents involved in the training.

In a summarized way you can see the different uses of this instrument according to (March, 2010; Mora et al., 2018): Purposes: to evaluate essays, individual works, brief group activities, extensive projects, oral presentations.

a) Areas: technical, scientific or humanities.

b) When: depending on the purpose of the evaluation and the proposed learning task. 
c) Types: Structure or degree of formality: analytical and holistic.

d) Thematic: generic (generic or cross-cutting competencies) and specific to the domain of subjects or tasks.

e) Amplitude: components of the competition or competence as a whole.

f) Uses: observation-evaluation; self-assessment, peer evaluation, etc.

\section{Co-evaluation}

Is one of the main scenarios for promoting the development and implementation of communicative competences of an interpretative, argumentative and purposeful nature, as well as critical thinking, competencies that are related to Training citizen (González \& González 2014; Ginaya et al., 2018) However, at the time of applying this coevaluative exercise with students and teachers, a positive attitude will be shown generating attitudes, criticisms of solidarity and dialogue where the end the primary of this working technique is to evaluate and rescue aspects that are relevant.

Co-evaluation as a formative experience, is based on dialogue and the exchange of opinions in turn it is a reciprocity that enables a reconstruction and collective feedback, Sanmartí (2007), argues that this activity you get a learning of affective socio dimensions where there is acceptance of the diversity of perspectives and criteria where the valuation of the learning of the other predominates. This assessment allows the student to take an active role in both individual and group learning, in turn encouraging and facilitating the student to have active participation in the learning process.

\section{Learning}

Learning is a process through which skills, skills, knowledge, behaviors and values are modified and acquired, in turn it is vital for humans, because it allows us to adapt and know how to act in the environment in which we live and in the different situations that we will have to face throughout our lives, wherein turn learning is considered a relevant aspect in the teaching process (García et al., 2015), Regardless of what manifested learning tends to be personal and individual where each individual develops their own knowledge and in different rhythms. Figure 1 shows the relevances of learning.

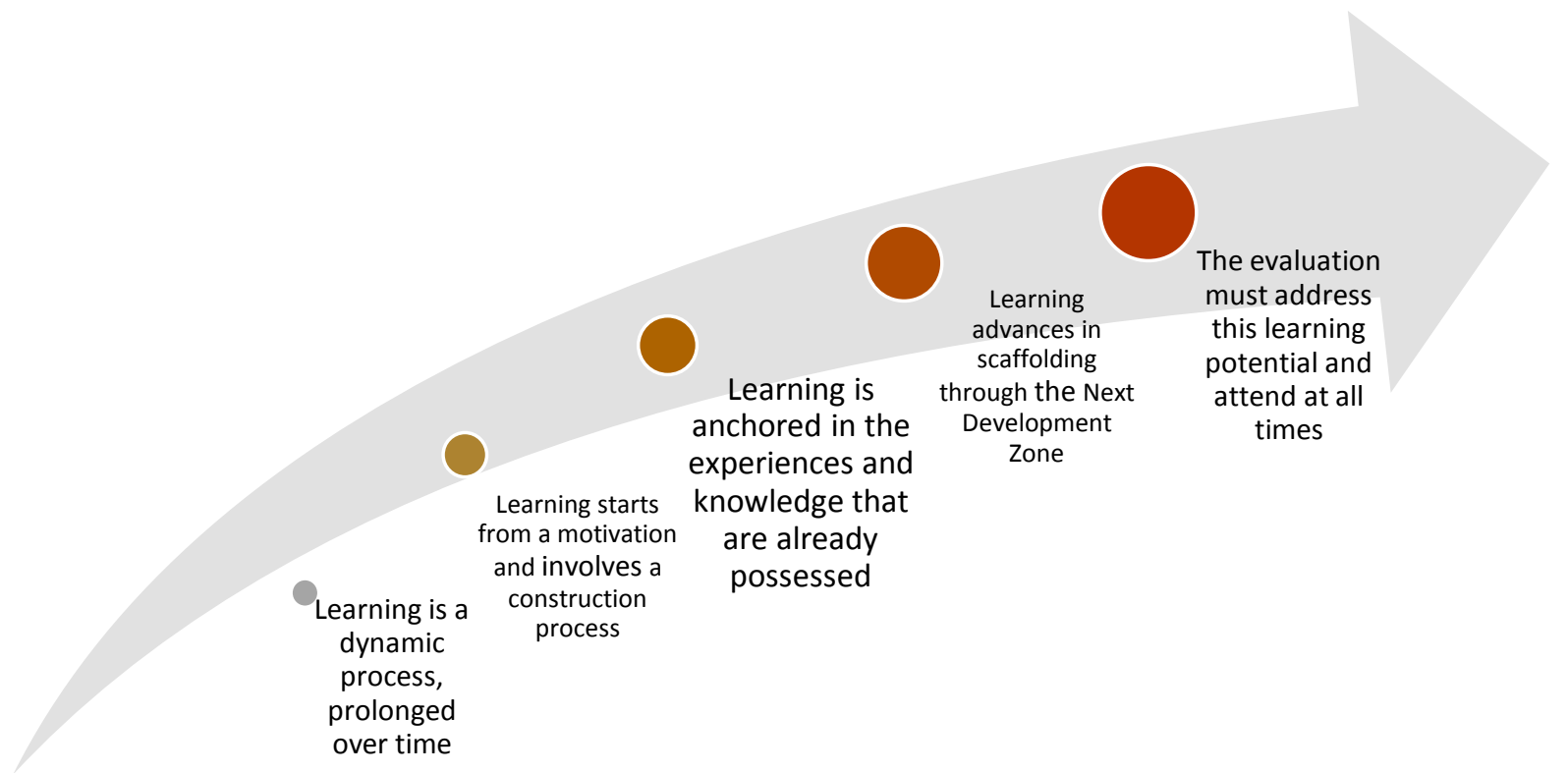

Figure 1. The relevance of learning

Source: (Lopez, 2017)

Vera, A. B. G., Vera, M. K. G., Garcia, A. M. R., \& Miranda, M. J. V. (2019). Application of self-evaluation and coevaluation on learning processes. International Journal of Linguistics, Literature and Culture, 5(5), 7-14. 


\section{Learning styles}

It is the way in which the individual perceives, processes integrates, and remembers information, the same that aims to provide a didactic, competent and more meaningful teaching to improve the academic performance of students and in that way give them greater confidence and perfect their chances of success by improving their ways of learning. Figure 2 shows the learning styles

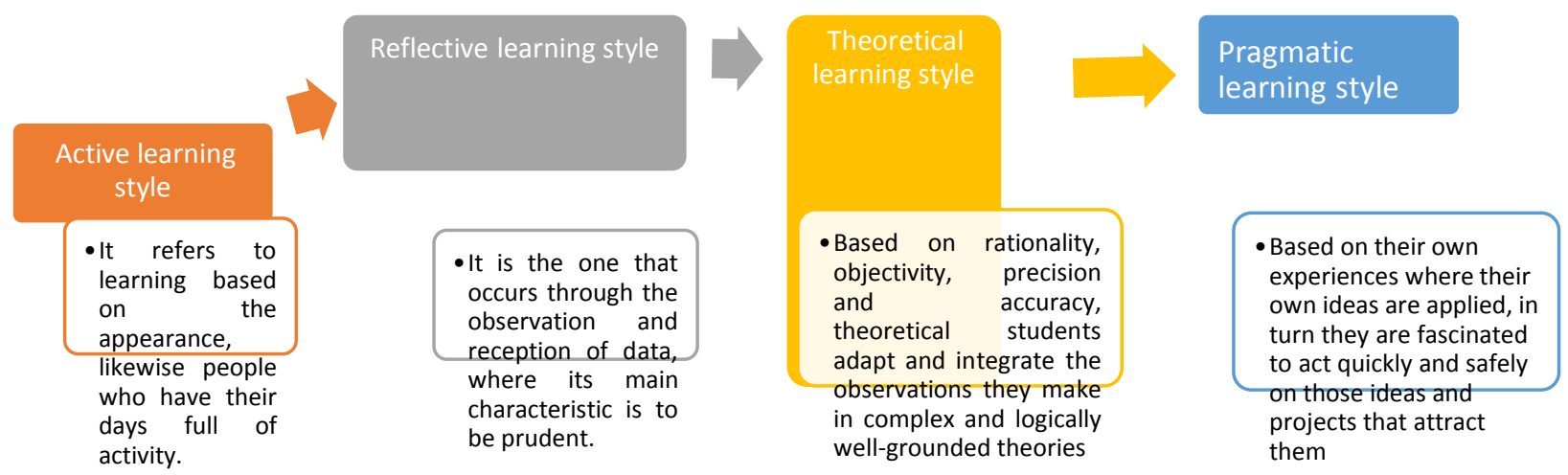

Figure 2. Learning styles

Source: (Domínguez et al., 2015)

The human being learns differently, each style has an unbiased value, none is better or less than another, the teacher must get the educators to become aware of their preferred learning styles, the same that must be flexible and people, like styles, unfold and transfigure over time. In turn, the styles, as well as the strategies followed, should vary depending on the subject that is offered, where students are aroused interest in the study and feel motivated day by day to gather new knowledge.

\section{Learning Strategies}

Learning strategies are those rules that allow you to make decisions about a particular process, defined in this very general way, these belong to the kind of knowledge called procedural that refers to how things are done (Díaz Barriga, 2010), mentions that teaching strategies can be applied before, during or after the topic covered, the same that support curriculum content by strengthening the motivational factors of the apprentice and reinforcing the learning process. Figure 3 shows The Essential Characteristics of Learning Strategies.

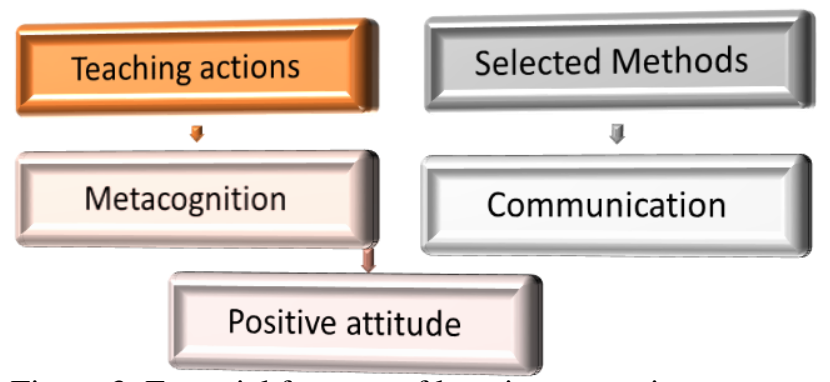

Figure 3. Essential features of learning strategies

Source: (Montes \& Machado, 2011)

\section{Teachings}

Teaching is one of the necessary ways to acquire knowledge in the learning process, where there are several processes that are carried out whenever person prepares to learn; students in doing their activities perform their 
activities multiple cognitive operations that make their minds develop easily. Teaching is as old as man, in turn, it is not possible for any teacher to arbitrarily decide what is right or wrong (Salas, 2012), the educational process is very complex and multifaceted where knowledge is transmitted, values, a custom of all kinds of social nature, which through the use of strategies is an integral part of learning activities and consist of techniques to create and maintain a positive teaching climate, through a dynamic and teacher performs in his constant pedagogical activities.

Strategies can be used at different times of teaching where teachers must include visual-spatial representation such as maps or semantic networks, linguistic representation, as summaries or synoptic tables thus achieving understanding that teaching is a continuous and dynamic process that leads to the beginning of the basic process of student training (Wiske, 2006).

\section{Results obtained}

The survey was applied to the 25 teachers of the Alijo Lascano Tax Educational Unit where 13 of them were male, while 12 were women. The first question asked was which evaluative practices were most commonly used in their teaching process, and the results were as follows:

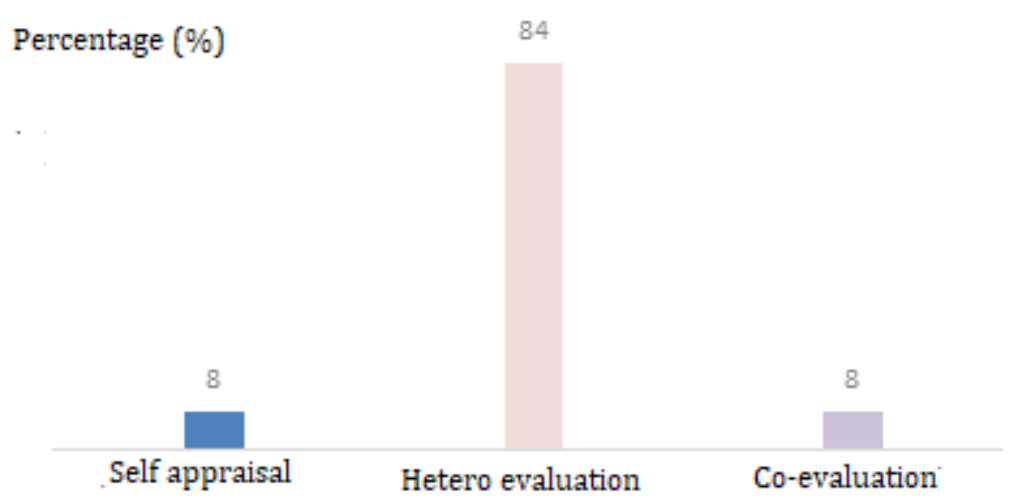

Figure 4. Use of Self-Assessment, Heteroevaluation, and Co-evaluation by teachers

$84 \%$ of teachers surveyed responded that they use Hetero evaluation as the only method when measuring knowledge and attitudes in students, while $8 \%$ use self-assessment and the remaining $8 \%$ of co-evaluation. These results determined that only teachers evaluate the different skills and abilities of students, thus limiting them to have their own learning, and denying them the ability to learn to listen to other people's opinions and suggestions such as (García et al., 2015).

The following question investigates the possible causes that make it impossible to use auto-evaluation and coevaluation in the educational process, which the results are shown below:

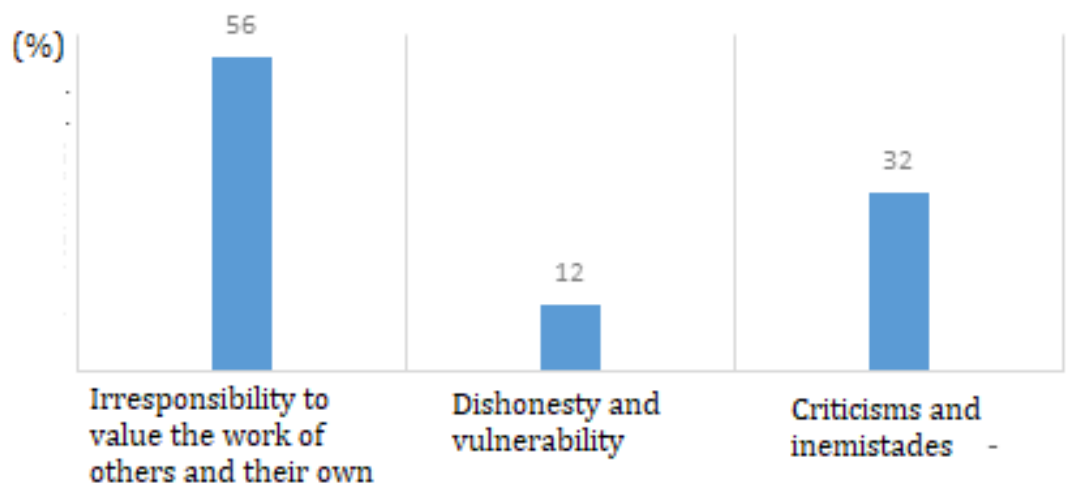

Figure 5. Reasons that make it impossible to use Self-Assessment and Co-evaluation

Vera, A. B. G., Vera, M. K. G., Garcia, A. M. R., \& Miranda, M. J. V. (2019). Application of self-evaluation and coevaluation on learning processes. International Journal of Linguistics, Literature and Culture, 5(5), 7-14. https://doi.org/10.21744/ijllc.v5n5.727 
$56 \%$ of teachers believe that students at the time of evaluating their own and other work will not act with the proper responsibility needed for this type of assessment. $12 \%$ believe that dishonesty can exist and that at the same time certain students may feel vulnerable to these processes, while $32 \%$ believe that these techniques would affect the classroom environment because of the criticisms and enmities that would be generated. According to these responses, it can be determined that teachers are not using the right strategies within the teaching-learning process as they indicate that teachers are solely responsible for using an appropriate and technical methodology, fostering an environment of values and principles in which students are the only ones who benefit from personal and academic growth.

The third question investigated the knowledge of the importance of Co-evaluation and self-assessment within the teaching-learning process by teachers in the Educational Unit and the results were that the $92 \%$ you know that he practices give the possibility to a self-learning as they indicate (Pastor et al., 2005), and that can at the same time be enriching when receiving external suggestions which would achieve in students a significant knowledge as stipulated (Sanmartí, 2007), while $8 \%$ did not have knowledge of the subject matter.

The last question investigated the possibility of applying the evaluation processes (Self-assessment, Coevaluation) from this research work, resulting in $100 \%$ of teachers answering that yes, therefore it will be achieved that students are the protagonists of their own learning and that at the same time get the ability to make value judgments and constructive criticisms to third parties as indicated (Rodríguez \& Hernández, 2014).

\section{Conclusion}

As observed in the results obtained from the surveys applied to teachers of the Fiscal Educational Unit "Alejo Lascano" it was possible to see: That teachers use self-assessment and co-evaluation in a minimum percentage within the process of evaluation, where it could also be determined that they are clear that both self-assessment and coevaluation achieve in students thought of autonomy, self-reflection, motivation, and commitment; however, not being clear about the rules and executing such assessments causes interest to be lost and you may be afraid to move from a comfortable and predictable situation to an unknown one.

\section{Conflict of interest statement}

The authors declared that they have no competing interest.

\section{Statement of authorship}

The authors have a responsibility for the conception and design of the study. The authors have approved the final article.

\section{Acknowledgments}

We extend our infinite thanks to the Pontificia Universidad Católica del Ecuador, Sede Manabí headquarters for the opportunity to learn how to carry out and present scientific research work; in the same way to Dr. María Rodriguez Gámez, professor of the Graduate for her dedication and understanding throughout the learning time. To ourselves to the managers of the Educational Unit Alejo Lascano give us the opening of doing our work in a prestigious institution. 


\section{References}

Avila-Salas, F., Sandoval, C., Caballero, J., Guiñez-Molinos, S., Santos, L. S., Cachau, R. E., \& González-Nilo, F. D. (2012). Study of interaction energies between the PAMAM dendrimer and nonsteroidal anti-inflammatory drug using a distributed computational strategy and experimental analysis by ESI-MS/MS. The Journal of Physical Chemistry B, 116(7), 2031-2039. https://doi.org/10.1021/jp2069122

Bordelois, M. I., Mustelier, J. J. B., \& Zevallos, I. V. (2018). The career self evaluation in improving the quality of higher education. International Journal of Social Sciences and Humanities, 2(1), 84-91. https://doi.org/10.29332/ijssh.v2n1.87

Díaz, F. Hernández. (2010). Teaching Strategies for Meaningful Learning. Mexico, McGraw-Hill Interamerican Editorial .

Figueira, MEM, González, FT, \& Rivas, MR (2013). The rubric as an instrument for self-assessment: a pilot study. REDU: Journal of University Teaching , 11 (2), 373.

García Gajardo, F., Fonseca Grandón, G., \& Concha Gfell, L. (2015). Learning and academic performance in higher education: a comparative study.

Ginaya, G., Rejeki, I. N. M., \& Astuti, N. N. S. (2018). The effects of blended learning to students' speaking ability. International Journal of Linguistics, Literature and Culture, 4(3), 1-14.

López, MSF (2017). Evaluation and learning. MarcoELE: Journal of Spanish Foreign Language Teaching , (24), 3.

Macías, EIP, Cedeño, HAC, \& Chávez, GMR (2018). Importance of Improving Resilience in Teaching-Learning Process of Students with Disabilities. International Research Journal of Management, IT and Social Sciences, 5 (2), 120-128.

March, AF (2010). The learning-oriented evaluation in a model of skills training in university education. REDU: Journal of University Teaching , 8 (1), 11-34.

Migueles, AR, \& Yulcerán, AH (2014). Demystifying some biases of self-assessment and co-evaluation in student learning. REXE Journal of Studies and Experiences in Education , 13 (25), 13-31.

Montes de Oca Recio, N., \& Machado Ramírez, EF (2011). Teaching strategies and teaching-learning methods in Higher Education. Medical Humanities , 11 (3), 475-488.

Mora, MM, Espinosa, MR, \& Delgado, MR (2018). Approach of Processes for the Distribution of Economic Resources in Public University of Ecuador. International Research Journal of Management, IT and Social Sciences , 5 (1), 25-35.

Núñez, FC, \& Urquijo, AQ (2012). Importance of evaluation and self-evaluation in academic performance. Near zone: magazine of the Institute of Higher Studies in Education , (16), 96-104.

Pastor, VML, Pascual, MG, \& Martín, JJB (2005). Student participation in the evaluation: self-assessment, coevaluation and shared evaluation. Rev. Tandem Teaching Educ. Fís, 17, 21-37.

Rodríguez, HDJD, Limón, JAG, Pisfil, ML, Torres, DV, \& Exume, JCD (2015). Learning styles: a diagnostic study in the university center of economic-administrative sciences of the $\mathrm{U}$ of G. Journal of higher education , 44 (175), 121-140. https://doi.org/10.1016/j.resu.2015.09.005

Sanmartí, N. (2007). 10 ideas clave: Evaluar para aprender. Coleccion ideas clave (España).

Velázquez, LG, \& Velazquez, MDRG (2016). Peer evaluation and co-evaluation in students and university teachers: a training experience to boost the educational model. International Journal of Developmental and Educational Psychology. INFAD Journal of Psychology. , 2 (1), 501-508.

Wiske, M. S., Franz, K. R., \& Breit, L. (2006). Teaching for Understanding with technology. Enseñar para la comprensión con nuevas tecnologías (No. Sirsi) i9789501255119).

Vera, A. B. G., Vera, M. K. G., Garcia, A. M. R., \& Miranda, M. J. V. (2019). Application of self-evaluation and coevaluation on learning processes. International Journal of Linguistics, Literature and Culture, 5(5), 7-14. 


\section{Biography of Authors}

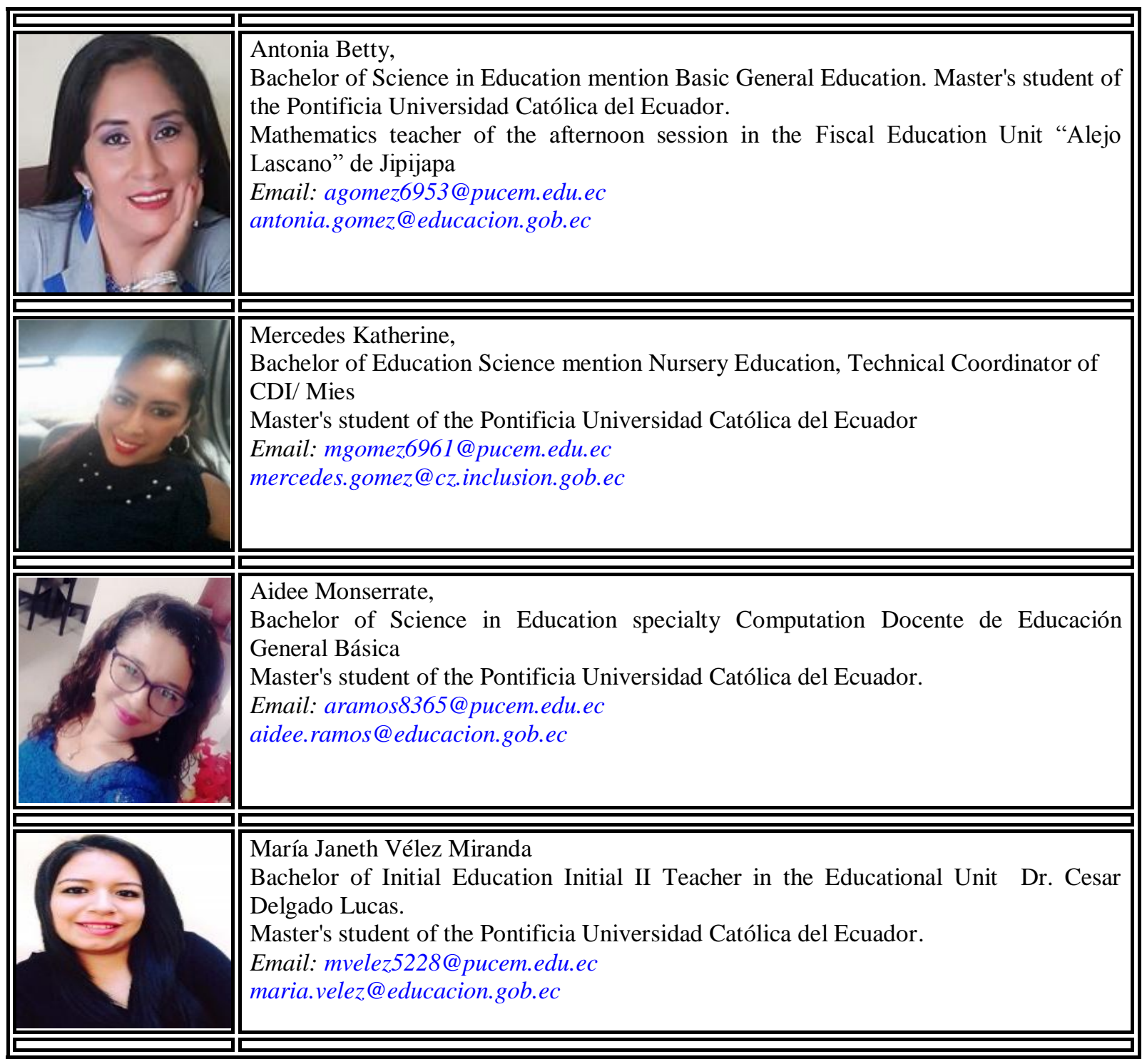

